\title{
Editorial: Welcome message from the new Editor-in-Chief
}

\author{
Nilanjana Maulik
}

(C) Springer Science+Business Media Dordrecht 2013

Dear Authors and Readers of $M B R$ :

On behalf of the entire community of Molecular Biology Reports, its Authors and Readers, I would like to thank the outgoing Editors-in-Chief, Drs. Gary S. Stein and André J. van Wijnen, who have graciously edited and nourished this Journal since March 2000. The Editors deserve a big round of applause for the enormous time and effort they have invested in this Journal, encouraging its growth in the field of Molecular Biology.

As the incoming Editor-in-Chief, I am very excited about this journey. Life is a journey with huge challenges and I accept the challenge to lead Molecular Biology Reports. I am committed to improving the quality of publication by becoming more selective in the acceptance of articles, increasing the Journal's Impact Factor, and keeping the Journal relevant in the field. Working alongside a dynamic Editorial Team consisting of a brilliant, internationally diverse Editorial Board and our Springer Publishing Editor, Ky'esha Hammond, we will achieve and exceed our goals!

Starting in 2014, the following new sections will be featured in $M B R$ :
- Short Communication

- Podcasts by Leading Scientists

- Special Issues

- Comprehensive Invited Reviews

- Methodological Reviews

Also, $M B R$ will be designed to revitalize the Journal and attract the new electronic generation to do powerful science, bringing software managements into focus. Science is creative, and as Editor-in-Chief, I will welcome suggestions, discussion, and thoughts from the authors and readers, to help me to understand and rectify any problems with the Journal.

So my dear authors, colleagues and friends, I warmly encourage all of you to bring the best science to the $M B R$ podium, improving the focus of this fine Journal in its field. As we all know, life is always about looking forward, accepting new changes, making us stronger and more complete. So let us look forward together to new successes and new achievements for this journal, as presented by our leading publisher, Springer.

Sante' and Merci!
N. Maulik ( $₫)$

Department of Surgery, University of Connecticut School of Medicine, 263 Farmington Avenue, Farmington, CT 06030, USA

e-mail: springermbr@gmail.com 